\title{
Networking for Philanthropy: Increasing Volunteer Behavior via Social Networking Sites
}

\author{
Yoojung Kim, $\mathrm{PhD}^{1}$ and Wei-Na Lee, $\mathrm{PhD}^{2}$
}

\begin{abstract}
Social networking sites (SNSs) provide a unique social venue to engage the young generation in philanthropy through their networking capabilities. An integrated model that incorporates social capital into the Theory of Reasoned Action is developed to explain volunteer behavior through social networks. As expected, volunteer behavior was predicted by volunteer intention, which was influenced by attitudes and subjective norms. In addition, social capital, an outcome of the extensive use of SNSs, was as an important driver of users' attitude and subjective norms toward volunteering via SNSs.
\end{abstract}

\section{Introduction}

$\mathbf{R}$ OUGHLY A QUARTER OF AMERICANS each volunteered an average of 51 hours during 2011. ${ }^{1}$ Volunteers generate services worth more than $\$ 173$ billion annually in the United States. ${ }^{2}$ For many nonprofit organizations, the work of volunteers has become vital to their success or even their survival due to governmental funding cuts and shrinking budgets. ${ }^{3-6}$ Moreover, volunteers are important potential donors, since they are more likely to make charitable gifts to nonprofits. ${ }^{7,8}$ Thus, it is critically important for nonprofits to engage volunteers at all levels.

The unique social nature and mounting popularity of social networking sites (SNSs) have begun to provide the connections that can be exploited to promote social change. Not surprisingly, nonprofits have learned to use SNSs as a way to connect with volunteers. For example, Facebook users, through the "Causes" application, can add to their online profile to create a cause (or join an existing one), and recruit potential volunteers and donors. Launched in 2007, "Causes" have had 170 million registrations to 500,000 causes, and they raised \$40 million in 2012. ${ }^{9}$

This burgeoning success demonstrates the potential of SNSs for engaging primarily young people in philanthropy. While the younger generation is less likely to donate cash to nonprofits given their limited earning power, they possess a particular positive attitude toward volunteering. ${ }^{10}$ Nonprofits also realize the importance of building relationships with young people, which, over time, may develop into lifetime partnerships necessary for the organization's long-term success. ${ }^{10} \mathrm{SNS}$ s thus provide a useful means for nonprofits to engage with the younger generation and channel their collective power for socially desirable ends.
College students are known to be active users of SNSs. They are more likely than any other demographic segments to have SNS accounts, and spend significant amounts of time on such sites daily. ${ }^{11}$ In addition, the proportion of American college students volunteering has increased since 2001 from $27.1 \%$ to $30.2 \%{ }^{12}$ and it exceeds the volunteering rate for the general adult population of $28.8 \%{ }^{12}$ It is thus important to study this demographic segment to understand the role of SNSs in increasing volunteering behavior among young adults.

Despite its potential and significance, the question of what drives volunteering through SNSs has yet to be fully explored. ${ }^{13}$ The Theory of Reasoned Action (TRA) ${ }^{14}$ has been invoked to explain a wide range of behaviors based on a person's attitude toward the behavior and the subjective norms regarding it. ${ }^{15-19}$ This suggests that the TRA might be an appropriate theoretical framework to help explain why people volunteer via SNSs. The theory's key constructs may make it possible to pinpoint to what extent various factors differentially influence volunteering behavior via SNSs.

SNSs are social venues wherein the users maintain their existing relationships and extend their networks. As such, social relationships should be a critical factor to consider when studying the effects of SNS membership on volunteer behavior. This suggests that the TRA may need to be extended to incorporate social capital into the model. This study investigates the idea that social capital developed through the use of a SNS may affect attitudes and subjective norms as motives to influence one's behavior under the TRA. The goal of this study is thus to elucidate the mechanism of initiating volunteer behavior via SNSs in an attempt to provide needed insights into how SNSs can help engage prospective volunteers and benefit nonprofit organizations.

${ }^{1}$ Department of Media Communication, Konkuk University, Seoul, Korea

${ }^{2}$ Department of Advertising, The University of Texas at Austin, Austin, Texas. 


\section{The Theory of Reasoned Action}

The TRA posits that an individual's behavior is directly influenced by his or her intention to act, and that intention, in turn, is influenced by the individual's attitude toward the act and subjective norms about how one should act. ${ }^{14}$ Attitude is assumed to be a function of one's beliefs about the likelihood that the act will lead to various outcomes and one's evaluation of those beliefs. Subjective norms are an individual's perceptions of whether significant others think that one should perform a particular act. ${ }^{14}$ The subjective norms depend on salient beliefs about the normative expectations of an individual's specific referents, weighted by the motivation to comply with each referent's expectations. The TRA then represents decisions as intentions. Intentions are individual's expectations about one's own behavior in a given setting. ${ }^{14}$

In its original formulation the TRA does not include past behavior. However, such behavior may serve as an important predictor of intentions and future behavior. ${ }^{20}$ Action can emerge from both conscious and unconscious processes, and research has shown that the potential for a particular behavior can develop through direct or indirect paths. ${ }^{21}$ When people are motivated and able, they may systematically form a conscious intention to act based on a variety of factors, including past behavior. ${ }^{2-24}$ In predicting volunteering via SNSs, with a systematic process, past behavior may be a major determinant of intentions, and thus indirectly of actual volunteering. In addition, prior behavior may be evidence of an automatic response-the activation of a previously stored intention to act in a certain way at a future time when the appropriate situation arises. ${ }^{20}$ Past behavior may thus directly contribute to future behavior in contexts that support the development of habits. ${ }^{25,26}$ This review of the TRA and the influence of past behavior suggest the following hypotheses:

H1: Attitudes toward volunteering through SNSs are positively related to intention to volunteer through SNSs.

H2: Subjective norms about volunteering through SNSs are positively related to intention to volunteer through SNSs.

H3: Intention to volunteer through SNSs is positively related to actual volunteering through SNSs.

H4: Past volunteering behavior is positively related to (a) intention to volunteer and (b) actual volunteering through SNSs.

\section{Social capital and social networking sites}

The orientation and architecture of SNSs are geared toward social connectivity. Thus, social relationships might be expected to be a critical factor in understanding the effects of SNS membership on volunteering. The concept of social capital is useful in elucidating the nature of the social relationships formed and maintained in SNSs. According to Putnam, ${ }^{27}$ there are two types of social capital-bonding and bridging-which are closely linked to the strong and weak tie classification in social network research. ${ }^{28,29}$ Bridging social capital accumulates when individuals from different backgrounds make connections. ${ }^{27}$ Such weakly tied individuals may have tentative relationships, but bridging may broaden their social horizons or world views, and thus promote the diffusion of information. ${ }^{27,30}$ By contrast, bonding social capital accumulates through strongly tied networks. ${ }^{27}$ While strong ties have little diversity in their backgrounds, the bonding provides strong emotional support and mobilizes solidarity. ${ }^{27,30}$

In SNSs, through intensive use, bridging social capital may be augmented as a number of weak ties are easily formed and integrated into networks. Moreover, bonding social capital may also be strengthened because SNSs provide an additional effective channel for engaging with those with whom one already has strong ties. Therefore, active SNS participation may increase the member's perceived bridging and bonding social capital.

H5: The intensive use of SNSs is positively related to an individual's perception of the extent of bonding and bridging social capital.

In terms of the TRA, bonding and bridging relationships may have different influences on behavior. Bonding social capital is exclusive in nature, since it exists within a tightly connected network of strong ties. ${ }^{27,30}$ Conversely, bridging social capital is more inclusive, as it accumulates from connecting individuals from different backgrounds. ${ }^{27,30}$ This suggests that bonding social capital may be associated with subjective norms, where the beliefs or ideas of similar others are important and people are motivated to comply with them. Bridging social capital may be linked to adding new beliefs or changing the strength of existing beliefs and to the evaluation of new information. Thus, in the context of volunteering via SNSs, bonding social capital may be a stronger influence on subjective norms, while bridging social capital may be more consequential for shaping attitudes toward volunteering through SNSs.

H6: Bonding social capital is positively related to subjective norms about volunteering through SNSs.

H7: Bridging social capital is positively related to attitudes toward volunteering through SNSs.

\section{Method}

\section{Sample}

An online survey was conducted with a total of 309 undergraduates at a large American university. They were recruited from introductory marketing courses and completed the survey in return for extra credit. After eliminating incomplete questionnaires, a final sample of 290 respondents was used in the analysis. The respondents were between 19 and 33 years of age, with an average age of 21. Among them, 170 (58.6\%) were female. The majority described themselves as Caucasian (53.4\%), followed by Asian-American (19.7\%), HispanicAmerican (16.2\%), African-American (2.8\%), and others (7.9\%).

\section{Measures}

The key variables of the TRA-attitude, subjective norms, and intention-were assessed in the context of volunteering through SNSs using items borrowed from prior research ${ }^{20,31}$ and modified to fit the context of this study. Past volunteering behavior and actual volunteering through SNSs were measured by using items adapted from the previous work. ${ }^{20}$ Social capital in the SNS context was measured by adapting an online bridging and bonding social capital scale tested in previous scholarly work, ${ }^{30,32}$ and SNS usage intensity was assessed using measures developed by prior study. ${ }^{32}$ For 
Table 1. Measures, Factor Loadings, Descriptive Statistics, and Reliabilities

\begin{tabular}{|c|c|c|c|}
\hline \multicolumn{2}{|l|}{ Factors } & \multirow{2}{*}{$\frac{\text { Unstd. }}{1.00^{\mathrm{a}}}$} & \multirow{2}{*}{$\frac{S t d .^{*}}{0.95}$} \\
\hline SNS usage intensity & This SNS has become part of my daily routine. & & \\
\hline$(M=5.44, S D=1.35$ & I feel out of touch when I haven't logged onto this SNS for a while. & 0.92 & 0.69 \\
\hline$\alpha=0.87)$ & $\begin{array}{l}\text { This SNS is part of my everyday activity. (Strongly Disagree=1, Strongly } \\
\text { Agree }=7 \text { ) }\end{array}$ & 0.98 & 0.92 \\
\hline \multirow{3}{*}{$\begin{array}{l}\text { Bridging } \\
\quad(M=4.81, S D=1.25, \\
\quad \alpha=0.85)\end{array}$} & I am interested in what goes on at this SNS. & $1.00^{\mathrm{a}}$ & 0.78 \\
\hline & coc moront to tro & 1.12 & 0.83 \\
\hline & $\begin{array}{l}\text { Interacting with people on this SNS makes me feel like part of a larger community. } \\
\quad(\text { Strongly Disagree }=1 \text {, Strongly Agree }=7 \text { ) }\end{array}$ & 1.13 & 0.81 \\
\hline \multirow{3}{*}{$\begin{array}{l}\text { Bonding } \\
\quad(M=5.03, S D=1.43, \\
\quad \alpha=0.82)\end{array}$} & There are several people at this SNS I trust to help solve my problems. & $1.00^{\mathrm{a}}$ & 0.76 \\
\hline & $\begin{array}{l}\text { There is someone at this SNS I can seek for advice about making important } \\
\text { decisions. (Strongly Disagree }=1 \text {, Strongly Agree =7) }\end{array}$ & 1.13 & 0.88 \\
\hline & If I needed an emergency loan of $\$ 100$, I know someone at this SNS I can turn to. & 1.12 & 0.72 \\
\hline \multirow{4}{*}{$\begin{array}{l}\text { Attitude } \\
\quad(M=5.21, S D=1.45 \\
\quad \alpha=0.96)\end{array}$} & Volunteering for nonprofit organizations through a SNS is... & & \\
\hline & Foolish/Wise (Foo & $1.00^{\mathrm{a}}$ & 0.88 \\
\hline & Useless/U & & 0.95 \\
\hline & Worthless $/$ Valuable $($ Worthless $=1$, Valuable $=7$ ) & & 0.98 \\
\hline \multirow{3}{*}{$\begin{array}{l}\text { Subjective norms } \\
\qquad(M=4.25, S D=1.27, \\
\quad \alpha=0.84)\end{array}$} & My family/close friends think I should volunteer to nonprofits through the SN & $1.00^{\mathrm{a}}$ & 0.95 \\
\hline & My family/close friends' opinions concerning volunteering through the SNS & 0.8 & 0.74 \\
\hline & $\begin{array}{l}\text { My family/close friends may disapprove of my volunteering to nonprofits through } \\
\text { the SNS. (Reversed) (Strongly Disagree }=1 \text {, Strongly Agree }=7 \text { ) }\end{array}$ & 0.86 & 0.74 \\
\hline \multirow{4}{*}{$\begin{array}{l}\text { Past volunteer } \\
\text { behavior }(M=2.29 \\
S D=1.57, \alpha=0.90)\end{array}$} & If you have volunteered to any nonprofit organizations in the past year... & & \\
\hline & $\begin{array}{l}\text { How many nonprofit organizations have you volunteered? }(0=1,>10 \text { nonprofit } \\
\text { organizations }=7)\end{array}$ & $1.00^{\mathrm{a}}$ & 0.77 \\
\hline & $\begin{array}{l}\text { How often have you volunteered to the organization? (never }=1 \text {, once a year }=2 \text {, } \\
\text { twice a year }=3 \text {, once a month }=4,2-3 \text { times a month }=5 \text {, once a week }=6,2-3 \\
\text { times a week }=7 \text { ) }\end{array}$ & 1.94 & 0.94 \\
\hline & How many hours have you volunteered? $(0=1,>60$ hours $=7)$ & 2.14 & 0.96 \\
\hline \multirow{3}{*}{$\begin{array}{l}\text { Volunteer intention } \\
\qquad(M=5.20, S D=1.38 \\
\alpha=0.92)\end{array}$} & $\begin{array}{l}\text { All things considered, I will volunteer for nonprofits through the SNS in the near } \\
\text { future. (Strongly Disagree }=1 \text {. Strongly Agree }=7 \text { ) }\end{array}$ & $1.00^{\mathrm{a}}$ & 0.94 \\
\hline & I intend to volu & 0.99 & 0.96 \\
\hline & I am willing to volunteer for nonprofits through the SNS in the near future. & 0.84 & 0.77 \\
\hline \multirow{4}{*}{$\begin{array}{l}\text { Actual volunteer } \\
\text { behavior via SNS } \\
(M=1.71, S D=1.18 \\
\alpha=0.75)\end{array}$} & If you have joined any nonprofit group pages (communities) through the SNS... & & \\
\hline & $\begin{array}{l}\text { How many nonprofit organizations joined via SNSs? }(0=1,>10 \text { nonprofit } \\
\text { organizations }=7)\end{array}$ & $1.00^{\mathrm{a}}$ & 0.77 \\
\hline & $\begin{array}{l}\text { How often have you volunteered for nonprofits joined via SNSs? (never }=1 \text {, once a } \\
\text { year }=2 \text {, twice a year }=3 \text {, once a month }=4,2-3 \text { times a month }=5 \text {, once a } \\
\text { week }=6,2-3 \text { times a week }=7 \text { ) }\end{array}$ & 0.73 & 0.74 \\
\hline & $\begin{array}{l}\text { How many hours have you volunteered for nonprofits joined via SNSs? }(0=1,>60 \\
\text { hours }=7)\end{array}$ & 0.80 & 0.65 \\
\hline
\end{tabular}

Note. All coefficients are significant at $p<0.001$ and generated from a final confirmatory factor analysis.

${ }^{a}$ Reference indicator.

Goodness of fit statistics: $\chi^{2}(224)=393.64, p<0.001, \mathrm{GFI}=0.90, \mathrm{TLI}=0.96, \mathrm{CFI}=0.97, \mathrm{RMSEA}=0.05$.

Unstd., unstandardized coefficient; Std., standardized coefficient.

each of the variables, only items with a Cronbach's alpha exceeding 0.70 were retained in the model to reach acceptable levels of reliability. ${ }^{33}$ Demographic data were also collected. Table 1 presents the specific items, descriptive statistics, and reliability coefficients.

\section{Results}

\section{Use of social networking sites}

Prior to examining the hypotheses, descriptive information on SNS use was obtained. Facebook ranked as the most frequently used SNS $(255,87.9 \%)$, followed by Twitter $(22,7.6 \%)$ and YouTube $(13,4.5 \%)$. On average, the respondents reported using their most-visited SNS for about 2 hours daily and having begun using the site more than 4 years ago. Of the
290 respondents, $135(47 \%)$ claimed to have volunteered during the previous 12 months, and 100 (35\%) said they had joined at least one nonprofit group through a SNS.

\section{Measurement model}

Before testing the hypothesized relationships, analyses were conducted to assess if the scales achieved satisfactory levels of reliability and if factor loadings were significantly related to their corresponding constructs. The proposed model was then tested with AMOS v19 using the two-step model-building approach. ${ }^{34}$ The measurement model, including the latent constructs and their respective observed variables, was analyzed first. Following that, the structural model with the hypothesized relationships was tested. 
Table 2. Correlation-Variance-Covariance Matrix for Latent Constructs

\begin{tabular}{|c|c|c|c|c|c|c|c|c|}
\hline & 1 & 2 & 3 & 4 & 5 & 6 & 7 & 8 \\
\hline 1. SNS usage intensity & $1.73^{* * *}$ & $0.90^{* * *}$ & $0.65^{* * *}$ & $0.22^{*}$ & 0.20 & 0.13 & $0.31^{* *}$ & $0.29^{*}$ \\
\hline 2. Bridging & 0.64 & $1.13^{* * *}$ & $0.64^{* * *}$ & $0.30^{* *}$ & $0.47^{* * *}$ & 0.11 & $0.45^{* * *}$ & $0.31^{* *}$ \\
\hline 3. Bonding & 0.40 & 0.50 & $1.49^{* * *}$ & $0.21^{*}$ & $0.31^{* *}$ & $0.16^{*}$ & $0.38^{* * *}$ & $0.38^{* *}$ \\
\hline 4. Attitude & 0.13 & 0.22 & 0.13 & $1.70 * * *$ & $0.63^{* * *}$ & 0.08 & $0.69^{* * *}$ & $0.47^{* * *}$ \\
\hline 5. Subjective norms & 0.12 & 0.34 & 0.19 & 0.37 & $1.71^{* * *}$ & $0.22^{* *}$ & $1.33^{* * *}$ & $0.33^{* *}$ \\
\hline 6. Past volunteer behavior & 0.11 & 0.12 & 0.15 & 0.17 & 0.19 & $0.81^{* * *}$ & $0.32^{* * *}$ & $0.48^{* * *}$ \\
\hline 7. Volunteer intention & 0.17 & 0.30 & 0.22 & 0.38 & 0.72 & 0.25 & $1.98^{* * *}$ & $0.61^{* * *}$ \\
\hline $\begin{array}{l}\text { 8. Actual volunteer } \\
\text { behavior via SNS }\end{array}$ & 0.17 & 0.22 & 0.24 & 0.27 & 0.19 & 0.40 & 0.33 & $1.73^{* * *}$ \\
\hline
\end{tabular}

Note. Variances are on the diagonal. Correlations are in the lower triangle, and covariances are in the upper triangle. ${ }^{*} p<0.05 ;{ }^{* *} p<0.01 ;{ }^{* * *} p<0.001$.

SNS, social networking site.

\section{Model verification}

The results of a confirmatory factor analysis indicate that the measurement model achieved satisfactory fit $\left(\chi^{2}=393.64\right.$, $d f=224, p<0.001 ; \mathrm{GFI}=0.90 ; \mathrm{TLI}=0.96 ; \mathrm{CFI}=0.97 ; \mathrm{RMSEA}=$ $0.05)$. All of the indicators significantly loaded on their corresponding latent constructs $(p<0.001)$, and the construct reliability (CR) and average variance extracted (AVE) were also assessed for convergent validity. The CRs for all constructs ranged from 0.75 to 0.96 , and the AVEs were greater than or equal to $0.50 .^{35}$ Thus, the variance captured by each dimension was significantly greater than the variance due to measurement error, indicating adequate convergent validity for each dimension. In addition, all square roots of the AVEs were higher than the correlations with other constructs, confirming discriminant validity. ${ }^{35}$ Table 2 presents the correlations, covariances, and variances of the latent constructs used in the measurement model.

\section{Hypothesis testing}

Structural equation modeling (SEM) was used to determine the overall relationship structure of the eight latent variables. The results show that all the hypothesized relationships between the latent constructs were statistically significant and in the expected direction (see Fig. 1). With respect to the fit statistics for the full model, the goodness-offit indices $\left(\chi^{2}=492.56, d f=242, p<0.001 ; \mathrm{GFI}=0.88\right.$; TLI =0.94; $\mathrm{CFI}=0.95$; RMSEA =0.06) demonstrated a good fit.

The first four hypotheses discuss the key variables of the TRA. As expected, attitude $(\beta=0.16, \mathrm{SE}=0.05, p<0.001)$ and subjective norms $(\beta=0.69, \mathrm{SE}=0.06, p<0.001)$ both showed significant positive impacts on intention. Intention $(\beta=0.23$, $\mathrm{SE}=0.06, p \leq 0.001)$ also showed significant effects on actual volunteering behavior via SNSs. Thus, H1-H3 were all supported. In addition, past volunteering was found to have the expected significant relationship with intention $(\beta=0.21$, $\mathrm{SE}=0.07, p<0.01)$ and actual volunteering via SNSs $(\beta=0.49$, $\mathrm{SE}=0.09, p<0.001)$, in support of $\mathrm{H} 4 \mathrm{a}$ and $\mathrm{b}$. These results suggest that SNS users may rely on their attitudes and subjective norms in forming an intention to volunteer via SNSs, and that intention leads to actual volunteering, as hypothesized. Also, past volunteering experience may influence actual volunteering via SNSs directly and indirectly through intentions.

The antecedents of the TRA variables are addressed in H5H7. Specifically, the intensity of SNS use was significantly related to both bridging $(\beta=0.53, \mathrm{SE}=0.05, p<0.001)$ and bonding social capital $(\beta=0.39, \mathrm{SE}=0.06, p<0.001)$, in

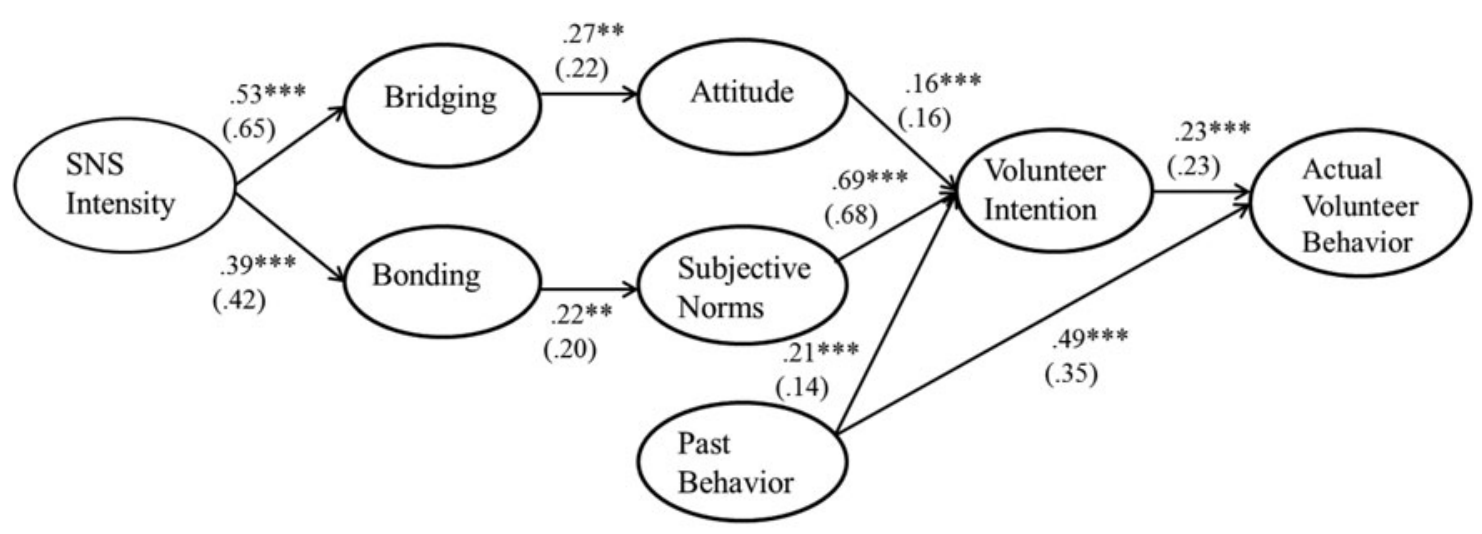

Model Fit: $x^{2}=492.56$, d.f. $=242, p<.001 ;$ GFI $=.88 ;$ TLI $=.94 ;$ CFI $=.95 ;$ RMSEA $=.06$

Notes: Unstandardized coefficients and standardized coefficients in parentheses are shown. ${ }^{*} \mathbf{P}<.05, * * \mathrm{P}<.01, * * * \mathbf{P}<.001$

FIG. 1. Results of structural equation analysis. 
support of H5. Furthermore, bonding social capital influenced subjective norms positively $(\beta=0.22, \mathrm{SE}=0.07, p<0.01)$, supporting H6. The relationship between bridging social capital and attitudes toward volunteering via SNSs was positive and significant $(\beta=0.27, \mathrm{SE}=0.07, p<0.001)$. This supports H7. The results imply that SNS users' intensive use of SNSs increases their social capital. In addition, bridging social capital significantly influences attitudes toward volunteering, and bonding social capital affects subjective norms about volunteering via SNSs.

\section{Alternative models}

In SEM, multiple models may fit the data equally well. Thus, alternative models were also tested to ensure that the model reported in Figure 1 fits the data best. ${ }^{36}$ The first alternative model tested whether past behavior had a sole direct relationship with actual volunteering. This analysis was intended to rule out the effect of past volunteering on intention to see if past behavior reflects an automatic and direct response, such as a habit or routine. ${ }^{20}$ The second alternative model, in contrast, tested whether past behavior had an indirect effect on actual volunteering through intention, controlling for the direct effect of past behavior on actual volunteering.

Smaller values of AIC and significant chi square differences are indicative of a better-fitting model. ${ }^{36}$ In this study, the AIC for the proposed model was 608.56 while it was 615.14 for alternative model 1 and 630.82 for alternative model 2. The proposed model also had the smallest $\chi^{2}$ (492.56), and the $\chi^{2}$ difference with alternative model 1 $\left(\chi^{2}=501.14\right)$ and model $2\left(\chi^{2}=516.82\right)$ was significant. Taken together, the results provide strong evidence supporting the proposed model as best at explaining the underlying process of volunteering behavior via SNSs.

\section{Discussion}

To understand factors influencing volunteering through SNSs, the TRA was employed as the core theoretical framework. The results demonstrate that the TRA is helpful in explaining individuals' volunteering through SNSs. The more positive SNS users' attitudes toward volunteering through SNSs, and the greater social pressure to volunteer they perceive, the more likely that SNS users will have the intention to volunteer. Having volunteer experience also seems to affect actual volunteering via SNSs directly and indirectly through intention.

Given the unique social nature of SNSs, the key predictors of volunteering behavior were explored by incorporating social capital considerations into the TRA. The findings of this study reveal that social capital produced by using SNSs plays a critical role in shaping attitudes toward and subjective norms about volunteering via SNSs. Bridging social capital shows a significant relationship with attitudes toward volunteering, while bonding social capital has a strong relationship with SNS users' subjective norms.

Interestingly, the results suggest that subjective norms have greater influence on intentions than attitudes or past behavior. Previous research on fast food consumption shows that subjective norms influences decisions when eating with friends but not when alone. ${ }^{20}$ In the context of fundraising, past research demonstrates that recognition plays an important role, since publicizing donor activities has a positive ef- fect on nonprofits' fundraising. ${ }^{37,38}$ Apparently, the social nature of SNSs seems to exert social pressure on volunteers' decisions. This could be because SNSs are in the public sphere where one's volunteer activities are easily recognized by peers. For young people, their preferred SNS may act as their hub on the Internet where they regularly visit and freely exchange information and experiences with their connections on a variety of topics. SNSs may thus provide an effective means for nonprofits to promote good causes and motivate young people to be involved in volunteering.

Practically, nonprofit managers should take notice that bridging and bonding social capital serve as important predictors of volunteering in different ways. The effect of bridging social capital seems to be related to the size of one's network of weak ties. As the number of SNS users "friending" an organization grows, the value of bridging social capital may improve. This implies that nonprofits could benefit from using popular SNSs such as Facebook to recruit and educate potential volunteers. Meanwhile, to increase the effect of bonding social capital, nonprofits could facilitate volunteering through invitations from close friend networks.

While the results of this study provide theoretical and practical insights, some limitations should be noted. The selfreported data measuring the respondents' behavior should be cautiously evaluated. ${ }^{39}$ Respondents may have been unwilling or unable to report accurately for ego-defensive or impression management reasons. ${ }^{39}$ Since volunteering behavior parallels many aspects of impression management, self-reports may overestimate positive attitudes toward volunteering or exaggerate the extent of actual volunteering activity. Employing experimental or observational research in the future should help reduce the potential for social desirability bias in the context of pro-social activities.

The survey methodology used in this study could not establish causality. This limitation could be better addressed by a longitudinal survey study to provide support for the causal relationships proposed here. Moreover, other unmeasured variables not controlled for in this design could display similar patterns and constitute common causes. For example, people who are outgoing with a large offline social network, or pro-social people in general, may use SNSs more often and be more likely to volunteer. Thus, examining other factors that influence volunteering online and offline should be worthwhile. Finally, future research might test the theory of planned behavior and its ability in explaining factors influencing volunteering via SNSs by incorporating perceived behavioral control. Previous research suggests that perceived self-control ability can be a crucial predictor of altruistic intentions. ${ }^{40}$ Thus, it appears promising for future research to employ the theory of planned behavior in this context.

\section{Author Disclosure Statement}

No competing financial interests exist.

\section{References}

1. Bureau of Labor Statistics. (2011) Volunteering in the United States. www.bls.gov/news.release/volun.nr0.htm (accessed Jul. 10, 2012).

2. National \& Community Service. (2011) Volunteering in America fact sheet. www.volunteeringinamerica.gov/ assets/resources/FactSheetFinal.pdf (accessed Jul. 10, 2012). 
3. Bendapudi N, Singh SN, Bendapudi V. Enhancing helping behavior: an integrative framework for promotion planning. Journal of Marketing 1996; 60:33-49.

4. Kerkhof DE, Kuiper, J. Improving the effectiveness of fundraising messages: the impact of charity goal attainment, message framing, and evidence on persuasion. Journal of Applied Communication Research 2008; 36:161-175.

5. Shearman SM, Yoo JH. "Even a penny will help!": legitimization of paltry donation and social proof in soliciting donation to a charitable organization. Communication Research Reports 2007; 24:271-282.

6. Webb, DJ, Green CL, Brashear TG. Development and validation of scales to measure attitudes influencing monetary donations to charitable organizations. Journal of the Academy of Marketing Science 2000; 28:299-309.

7. Freeman RB. Working for nothing: the supply of volunteer labor. Journal of Labor Economics 1997; 15:S140-166.

8. Webb CH. (2002) The role of alumni relations in fund raising. In Worth MJ, ed. New strategies for educational fund raising. Westport, CT: American Council on Education and Praeger Publishing, pp. 332-338.

9. Causes. (2010) Success stories. http://exchange.causes.com/ resources/success-stories (accessed Jul. 10, 2012).

10. The Center on Philanthropy. (2008) Generational differences in charitable giving and in motivations for giving. www .philanthropy.iupui.edu/Research / giving_fundraising research.aspx\#GivingByGeneration (accessed Jul. 2, 2011).

11. Facebook keeps its cool among college students. eMarketer, Dec.15, 2009. www.emarketer.com/Article.aspx?R $=1007418$ (accessed Jul. 10, 2012).

12. Dote L, Cramer K, Dietz N, et al. College students helping America www.eric.ed.gov/PDFS/ED494174.pdf (accessed Jul. 1, 2012).

13. Farrow H, Yuan YC. Building stronger ties with alumni through Facebook to increase volunteerism and charitable giving. Journal of Computer-Mediated Communication 2011; 16:445-464.

14. Ajzen I, Fishbein M. (1980) Understanding attitudes and predicting social behavior. Englewood Cliffs, NJ: Prentice-Hall.

15. Burnkrant RE, Page TJ Jr. The structure and antecedents of the normative and attitudinal components of Fishbein's TRA. Journal of Experimental Social Psychology 1988; 24:66-87.

16. Gastil J. Thinking, drinking, and driving: application of the TRA to DWI prevention. Journal of Applied Social Psychology 2000; 30:2217-2232.

17. Netemeyer RG, Burton S. Examining the relationships between voting behavior, intention, perceived behavioral control, and expectation. Journal of Applied Social Psychology 1990; 20:661-680.

18. Sheppard BH, Hartwick J, Warshaw PR. The TRA: a metaanalysis of past research with recommendations for modifications and future research. Journal of Consumer Research 1988; 15:325-340.

19. Miller LE, Grush JE. Individual differences in attitudinal versus normative determination of behavior. Journal of Experimental Social Psychology 1986; 22:190-202.

20. Bagozzi RP, Wong N, Abe $\mathrm{S}$, et al. Cultural and situational contingencies and the TRA: application to fast food restaurant consumption. Journal of Consumer Psychology 2000; 9:97-106.

21. Ouellette JA, Wood W. Habit and intention in everyday life: the multiple processes by which past behavior predicts future behavior. Psychological Bulletin 1998; 124: $54-74$.
22. Ajzen I. (1996) The theory of planned behavior: a bibliography. Unpublished manuscript, University of Massachusetts at Amherst.

23. Bargh JA, Chaiken S, Pratto F. The generality of the automatic attitude activation effect. Journal of Personality \& Social Psychology 1992; 62:893-912.

24. Fazio RH. (1990) Multiple processes by which attitudes guide behavior: the MODE model as an integrative framework. In Zanna MP, ed. Advances in experimental social psychology. San Diego, CA: Academic, pp. 75-109.

25. Bargh JA. (1989) Conditional automaticity: varieties of automatic influence in social perception and cognition. In Uleman JS, Bargh JA, eds. Unintended thought. New York: Guilford Press, pp. 3-51.

26. Logan GD. (1989) Automaticity and cognitive control. In Uleman JS, Bargh JA, eds. Unintended thought. New York: Guilford Press, pp. 52-74.

27. Putnam RD. (2000) Bowling alone: the collapse and revival of American community. New York: Simon \& Schuster.

28. Granovetter MS. Strength of weak ties. American Journal of Sociology 1973; 78:1360-1380.

29. Granovetter MS. The strength of weak ties: a network theory revisited. Sociology Theory 1983; 1:201-233.

30. Williams D. On and off the "Net": scales for social capital in an online era. Journal of Computer-Mediated Communication 2006; 11.

31. Shimp TA, Kavas A. The TRA applied to coupon usage. Journal of Consumer Research 1984; 11:795-809.

32. Ellison NB, Steinfield C, Lampe C. The benefits of Facebook "friends": social capital and college students' use of online social network sites. Journal of Computer-Mediated Communication 2007; 12.

33. Hair JF, Rolph EA, Ronald LT, et al. (1998) Multivariate data analysis. 5th ed. Upper Saddle River, NJ: Prentice-Hall.

34. Anderson JC, Gerbing DW. Structural equation modeling in practice: a review and recommended two-step approach. Psychological Bulletin 1988; 103:411-423.

35. Fornell C, Larcker DF. Evaluating structural equation models with unobservable variables and measurement error. Journal of Marketing Research 1981; 18:39-50.

36. Kline RB. (2005) Principles and practice of structural equation modeling. New York: Guilford Press.

37. Harbaugh WT. The prestige motive for making charitable transfers. The American Economic Review 1988; 88:277282.

38. Vesterlun L. The informational value of sequential fundraising. Journal of Public Economics 2003; 87:627-657.

39. Fisher RJ. Social desirability bias and the validity of indirect questioning. Journal of Consumer Research 1993; 20:303-315.

40. Aemitage, CJ, Conner, M. Efficacy of the theory of planned behavior: a meta-analytic review. British Journal of Social Psychology 2001; 40:471-499.

Address correspondence to: Dr. Yoojung Kim Assistant Professor

Department of Media Communication Konkuk University

120 Neungdong-ro, Gwangjin-gu Seoul 143-701

Korea

E-mail: ykim@konkuk.ac.kr 